\title{
A Study on Suction-rainfall Response of a Cut Slope in Unsaturated Residual Soil Using a Field Rain Simulator
}

\author{
${ }^{1}$ Bujang B.K. Huat, ${ }^{2}$ Faisal Hj. Ali and ${ }^{2}$ Mariappan, S. \\ ${ }^{1}$ Department of Civil Engineering, University Putra Malaysia \\ 43400 UPM Serdang, Selangor, Malaysia \\ ${ }^{2}$ Department of Civil Engineering, University of Malaya, 50603 Kuala Lumpur, Malaysia
}

\begin{abstract}
This research describes the design and construction of an artificial rain simulator system and the results obtained with regards to suction-rainfall response of a cut slope in unsaturated residual soil of weathered sandstone of various weathering grades. From the field measurements, the shallow tensiometers are found to record an immediate initial increase in matric suction within the first 20 min of the simulated rain before a gradual drop in suction takes place. However no such initial spikes in suction readings were recorded by the deeper tensiometers. With constant rainfall for the next $130 \mathrm{~min}$, a clear drop in soil suction was observed in all cases illustrating the effect of net infiltration process. Positive pore water pressure was even recorded by some of the deeper tensiometers. The suction recorded by the shallow tensiometers was always higher than those of the deeper tensiometers, indicating a reduction in suction with depth below the ground surface. In term of weathering grades, residual soil of weathered sandstone of weathering grade III has the highest infiltration rate indicating the more porous nature of this soil material. Like wise there is a steeper drop in suction during the rain at the said location.
\end{abstract}

Key words: Cut Slope, Infiltration, Landslide, Rainfall, Suction, Unsaturated Residual Soils

\section{INTRODUCTION}

Rainfall has been considered the cause of majority of slope failures and landslides that happened in regions experiencing high seasonal rainfalls $[1,2]$. Basically, it is well known that infiltration impairs slope stability, but since it often not measured off directly in the field, its assessment often relies on vague correlation with rainfalls and runoff. Correlation between rainfall and infiltration, thus slope stability involves large number of factors. Some of these factors such as rainfall duration and intensity, slope surface cover, degree of saturation, slope angle, permeability ratios and perched water table are extremely difficult to evaluate.

Conventionally, infiltration of water is not normally included in slope stability analysis. Many of the steep slopes were designed based on experiences. Most of the slopes failure or landslides occurred after prolonged heavy rainfall or antecedent rainfall. The mechanism of the failures is mainly due to the lost of matric suction of soils by rainwater. When the rainwater infiltrates into the slopes, it is known that it will start to saturate the soil, i.e., reduce the matric suction. The wetting front of rainwater will continue to move into the soil even after the rain has stopped. Movement of the wetting front stops when an equilibrium or steady state condition is achieved.

Matric suction is one of the main stress variables in unsaturated soil theory [3, 4]. The existence of matric suction will increase the strength of the soil. A deep ground water table condition is normal in hilly area of the tropical countries. In this case, the negative pore water pressure or matric suction plays an important role in controlling the soil shear strength and consequently the stability of many steep slopes. Shallow landslides often occur in steep residual soil slopes after heavy and prolonged rainfall. When water starts to infiltrate into the soil, the matric suction especially near the ground surface will slowly reduce and become zero as the soil approaches saturated condition. A significant reduction in matric suction is known to cause a decrease in soil shear strength that subsequently produces shallow landslides.

Studies on water infiltration have always been part of hydrology. Water infiltration forms the link between surface and subsurface hydrology. Infiltrated water must be quantified and subtracted from the surface runoff in flood prediction studies and surface water management. Numerous researchers have actually incorporated infiltration into the slope stability analysis of residual soil, e.g. Othman [5] and Anderson [6], Affendi and Ali [7], Suhaimi [8] and Ali and Rahardjo [9]. In most of the slope stability analysis, the infiltration rate of water into soil is assumed uniform throughout the slope. The soil is also assumed homogeneous except in some layered bedding problem. One of the main difficulties in conducting a study to examine the soil infiltration and suction relationship is in controlling the timing, duration and intensity of rainfall. Natural rain is of course unpredictable. Therefore in order to have a better control of the timing as well as intensity of the rain, an artificial rain 


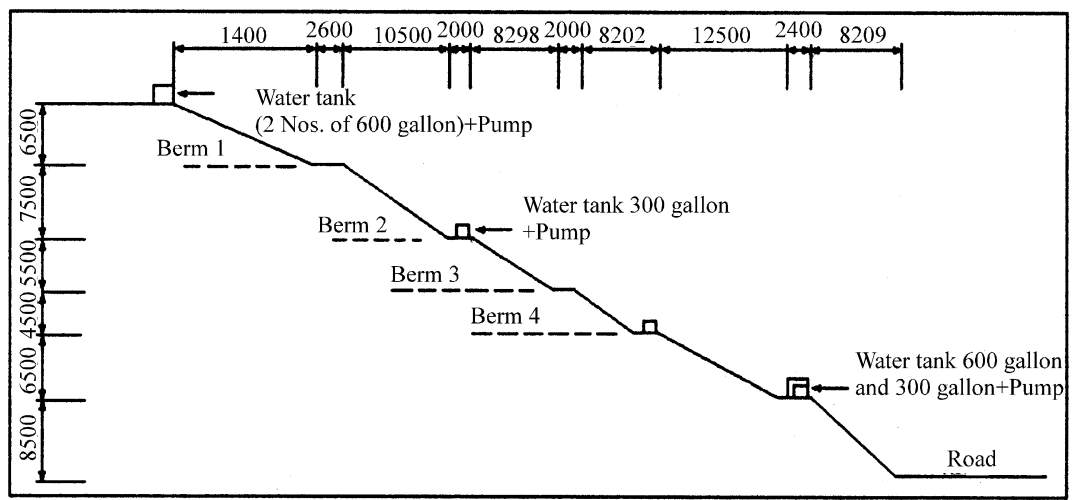

Fig. 1: Sectional Profile of the Cut Slope and Location of the Water Tanks

simulation system can be designed and built. Craig et al. [10] describes the design and construction of a laboratory rain simulator system for a laboratory centrifuge model. In the present study, a field rain simulator system was design and built. The rain simulator system was to provide a continuous artificial rain during the course of the experiment. Results were obtained with regards to suction-rainfall response of a cut slope in unsaturated residual soil.

Field Rain Simulator: The main objective of this study was to examine the influence of rain on the rate of soil suction changes with time due to the infiltration. In order to have a better control of the timing as well as intensity of the rain, as opposed to the unpredictable time and duration of natural rain, an artificial rain simulation system using a sprinkler method was designed and setup in the field. The rain simulator system was designed to provide a continuous artificial rain during the course of the experiment. The area within the rain simulator system was instrumented with shallow (small tip) and jet filled tensiometers, to measure the suction changes with time during the rain. A $122.4 \mathrm{~mm} \mathrm{~h}^{-1}\left(3.4 \times 10^{-5} \mathrm{~m} \mathrm{~s}^{-1}\right)$ rainfall was the highest recorded rainfall in five years (1995-2000) at the Subang Station by the Metrological Department of Malaysia, which is close to the field site, for the $1^{\text {st }}$ hour rain. The rain simulator was designed to impart the same intensity of rainfall for duration of $150 \mathrm{~min}\left(2 \frac{1}{2} \mathrm{~h}\right)$.

The rain simulator system basically comprise of water tanks, pumps and piping systems, sprinklers, flow meters and $\mathrm{V}-$ notch collection drains.

The field site was a cut slope of nearly $40 \mathrm{~m}$ high (Fig. 1). In order to have an adequate water supply to simulate an intensive rainfall for a duration of $90 \mathrm{~min}$ (at rate of $42 \mathrm{~L} \mathrm{~min}^{-1}$, i.e. for a catchments area of $15^{\prime} \mathrm{x}$ $15^{\prime}$, at rainfall intensity of $122.4 \mathrm{~mm} \mathrm{~h}^{-1}$ ) three numbers of 600 gallon and two numbers of 300 gallon water tanks were installed at the site as shown in Fig. 1. As the site has no water supply, water had to be brought in by tankers. A network of pipelines for water intake to the storage tanks and water supply to the test locations were laid using PVC pipes. Two sets of water pumps were used. One set was to pump water up the slope for the storage supply. The other set was to supply consistently $42 \mathrm{~L} \mathrm{~min}^{-1}$ of water to the sprinkler system. To simulate the rain, a sprinkler system was fabricated comprising of a $15^{\prime} \times 15^{\prime}$, sprinkling frame, made of steel tubes, PVC piping and sprinkler heads as shown in Fig. 2. and 3 shows a rainfall simulation in progress. Note that polythene sheets were used to enclose sides of the sprinkling/catchments area to minimize loss of water and direct surface run off to the collection drain. Fig. 4 shows a close up view of the sprinkler head.

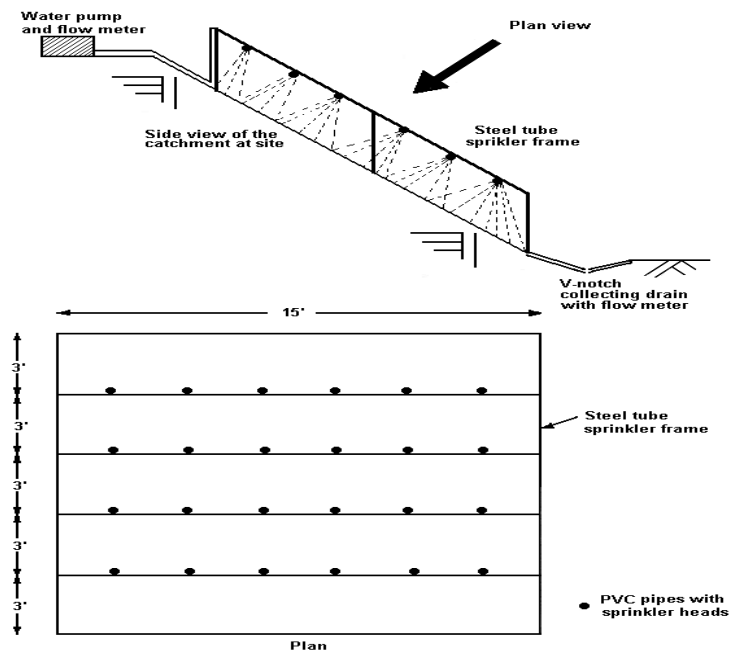

Fig. 2:Sprinkling Frame and Locations of Sprinkler Heads

To monitor the rate of water inflow and to regulate the flow to the test site, flow meters (Fig. 5) were installed. 


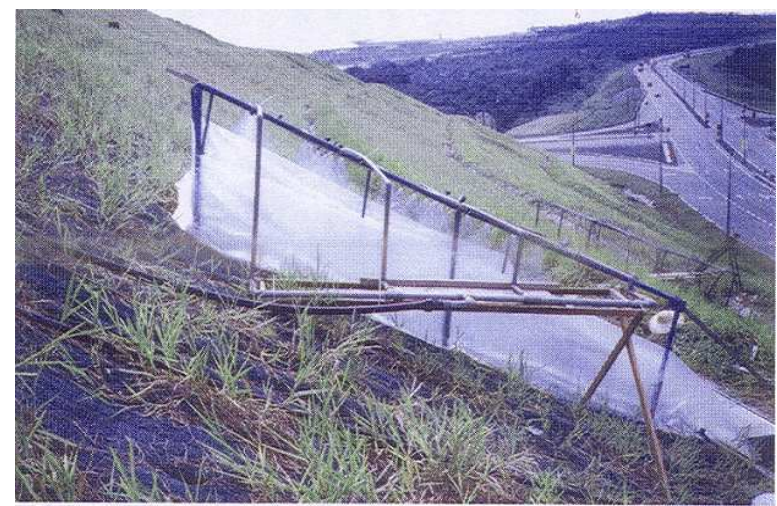

Fig. 3: Rainfall Simulation in Progress

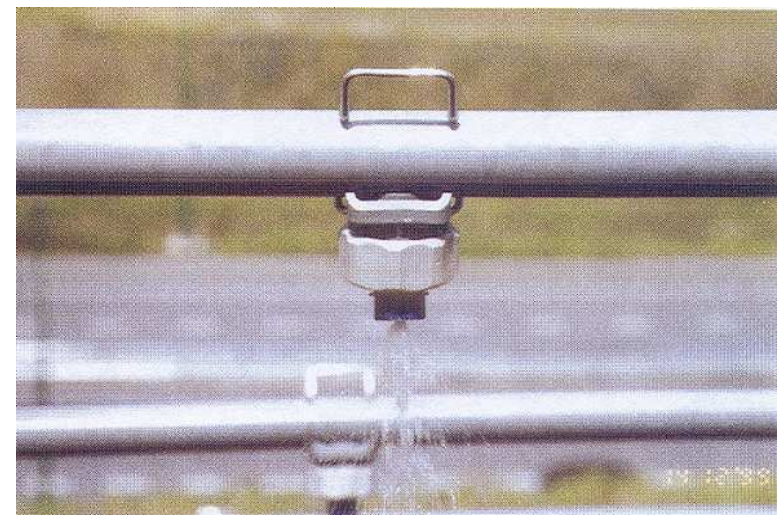

Fig. 4: Sprinkler Head

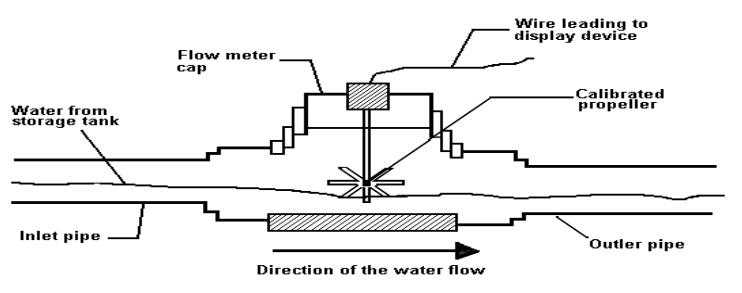

Fig. 5: Working Concept of a Flow Water

This enable the total volume of water supplied to the test locations to be measured. The excess (surface run off) water from the test site was in turn directed to vnotch collection drain and measured using the flow meter at the outlet.

Field Site and Instrumentation: The field site was a cut slope of approximately $40 \mathrm{~m}$ high along a link road near the Kuala Lumpur International Airport, Sepang, Malaysia. The slope basically comprise of residual soils of weathered sandstone. The soils are generally yellowish brown in color and consist mainly of fine sand and silt.
The cut slope was mapped for the weathering grades, based on the commonly used classification of Little [11], Komoo and Mogana [12].

Figure 1 shows a cross section of the cut slope. Base on the geological formation, the cut slope profile falls under the following weathering grades:

* Berm 1-Weathering grade V

* Berm 2-Weathering grade IV

* Berm 3-Intermediate weathering grade of IV and III

* $\quad$ Berm 4-Weathering grade III

To measure the soil suction, seven number of shallow small tip tensiometers (designated as 1-7) were installed at 10-inch $(254 \mathrm{~mm})$ depth within the $15^{\prime} \times 15^{\prime}$ catchment rainfall simulation area. In addition three numbers jet fill tensiometer were installed at $0.5 \mathrm{~m}(\mathrm{~A})$, $1.0 \mathrm{~m} \mathrm{(B)}$ and $2.0 \mathrm{~m} \mathrm{(C)} \mathrm{depth} \mathrm{into} \mathrm{the} \mathrm{soil.} \mathrm{Figure} 6$ shows locations of the tensiometers.

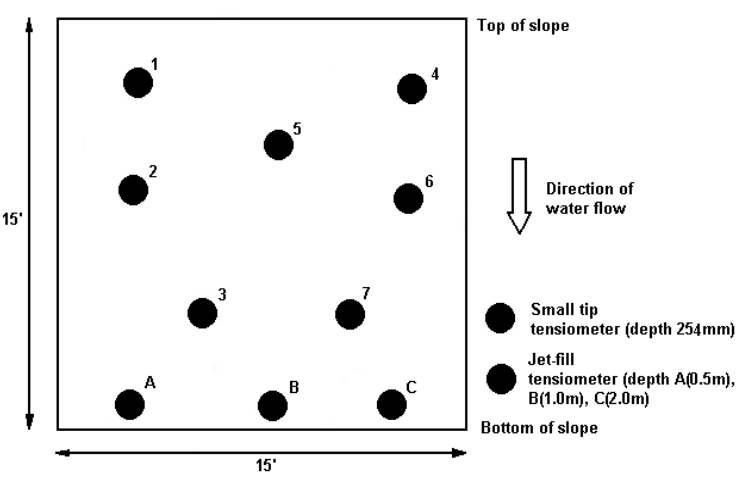

Fig. 6: Location of Small Tip and Jet Fill Tensiometer

Figure 7 shows detail of the small tip tensiometer. Figure 8 shows the jet-fill tensiometer. This tensiometer consists of a tube, sealed at one end by a porous ceramic cup, which comes in contact with the soil. The other end of the tube is above ground and connected to a vacuum dial gauge.

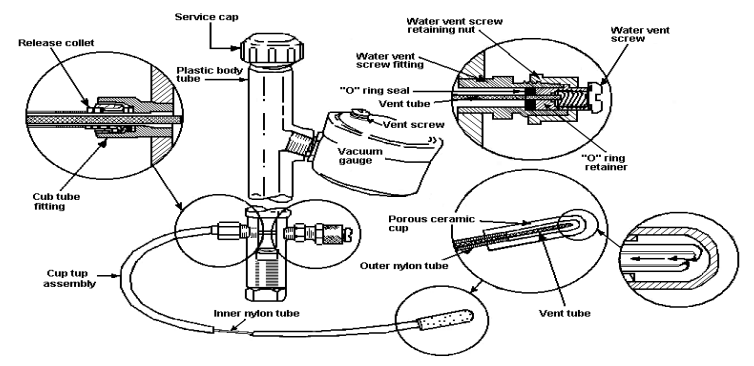

Fig. 7:Small tip tensiometer (Soil Moisture Equipment Corporation, USA) Source: www.soilmoisture.com 


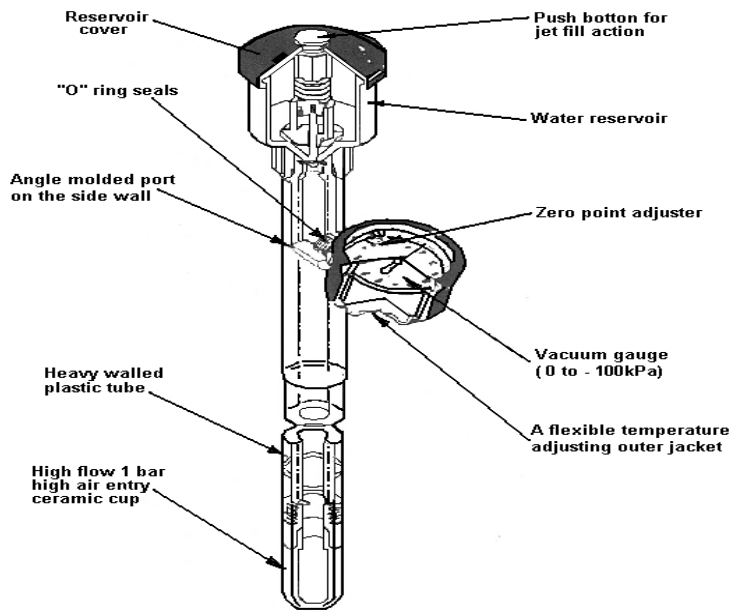

Fig. 8: Jet fill Tensiometer (Soil Moisture Equipment Corporation, USA)

Source: www.soilmoisture.com

Readings of the tensiometer were recorded at every $10 \mathrm{~min}$ and so were the rates of water inflow and outflow using an automated data-logging unit. Note that maximum suction that could possibility be measured by the tensiometer is 1 bar or $100 \mathrm{kPa}$.

Soil Suction Response to Simulated Rain: Figure 9 shows the soil suction response to simulated rain for test on berms 1, 2, 3 and 4, which roughly corresponds to residual soils of weathering grade V, IV, IV-III and III respectively. The trend matric suction change with time during the rain appears to be consistent. The shallow tensiometers (at $254 \mathrm{~mm}$ depth) appear to record an immediate initial increase in matric suction within the first $20 \mathrm{~min}$ of the rain before a gradual drop in suction take place. However no such initial spikes in suction readings were recorded by the deeper tensiometers (at depth of $0.5 \mathrm{~m}$ to $2.0 \mathrm{~m}$ ). With constant rainfall for the next $130 \mathrm{~min}$, a clear drop in soil suction was observed in all cases illustrating the effect of net infiltration process. Positive pore water pressures were even recorded some of the deeper tensiometers.

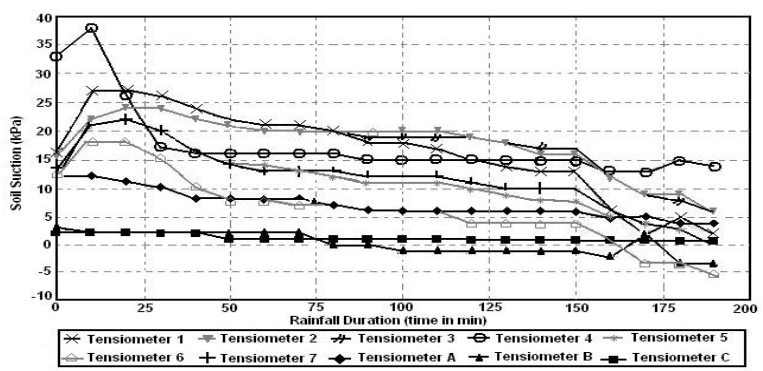

(a) Berm 1 (Weathering grade V)

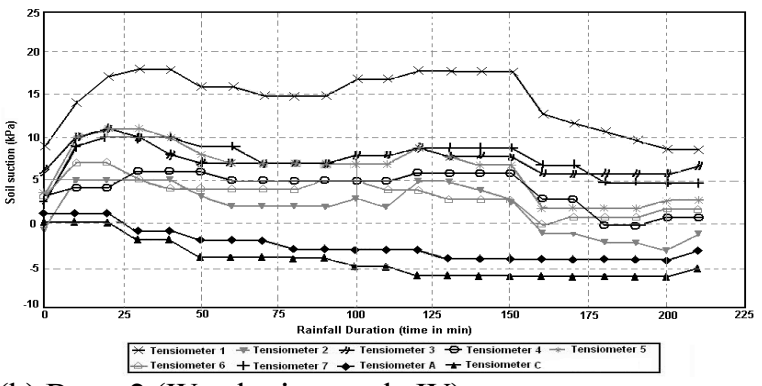

(b) Berm 2 (Weathering grade IV)

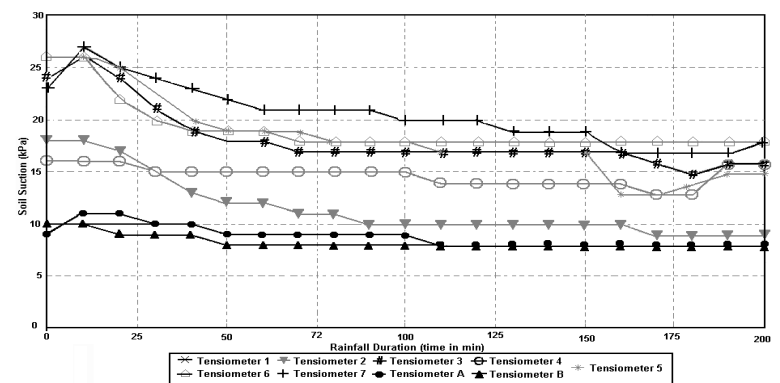

(c) Berm 3 (Intermediate weathering grade IV \& III)

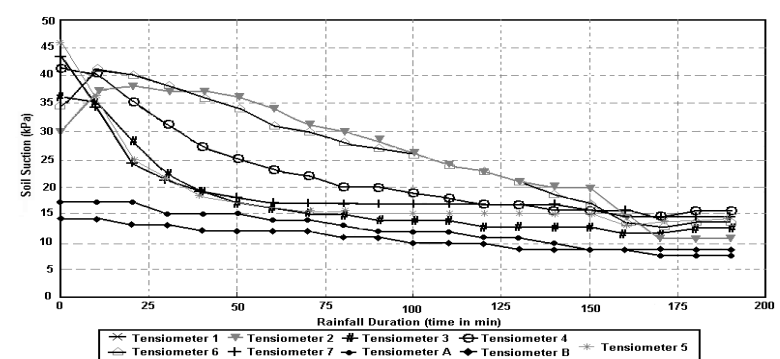

(d) Berm 4 (Weathering grade III)

Fig. 9: Soil suction response to simulated rainfall

After the rain has stopped at $150 \mathrm{~min}$, the suction appears to continue to drop for the next $30 \mathrm{~min}$ or so in particular at location of the shallow tensiometers, followed there after by a gradual rise in suction, albeit at a slow rate as the drying process begins.

It is also of interest to note that in all cases the suction recorded by the shallow tensiometers were always higher than those of the deeper tensiometers, indicating a reduction with depth below the ground surface. A similar observation of suction reduces with depth has been reported in Hong Kong [13].

The sudden increase of suction at the beginning of rain and the drop in suction after rain (a sudden drop in some cases) at the shallow depths is believed to be cause by lamina flow of rainwater at the slope surface. The flow creates lower pressure zone at the surface, which initially increases the soil matric suction. However a stop of the surface water flow (when the rain has stopped) releases the low pressure zone at the surface, causing an immediate drop in soil suction as 
the surface water rushes into the ground. The phenomenon also increases the water infiltration rate into the slope, causing further drop in suction or increase in positive pore water pressure immediately after the rain.

Table 1 summarizes the rate of infiltration of the soil slope estimated base on the surface run off. It appears that berm 4 of weathering grade III has the highest infiltration rate indicating the more porous nature of this soil material. Like wise there appear to be a steeper drop in suction during the rain at this location (berm 4) as shown in Fig. 9 (d).

Table 1: Summary of Soil Infiltration Rate

\begin{tabular}{lcc}
\hline Berm & Weathering grade & Infiltration rate $\left(\mathrm{m} \mathrm{s}^{-1}\right)$ \\
\hline 1 & V & $1.20 \times 10^{-6}$ \\
2 & VI & $2.30 \times 10^{-6}$ \\
3 & IV - III & $4.61 \times 10^{-6}$ \\
4 & III & $6.91 \times 10^{-6}$ \\
\hline
\end{tabular}

\section{CONCLUSION}

From the results of this study, the following conclusions can be drawn.

An artificial rain simulator system has been successfully design and constructed to study the suction-rainfall response of a cut slope in unsaturated residual soil of weathered sandstone.

The shallow tensiometers appear to record an immediate initial increase in matric suction within the first 20 min of rain before a gradual drop in suction takes place. However no such initial spikes in suction readings were recorded by the deeper tensiometers. With constant rainfall for the next $130 \mathrm{~min}$, a clear drop in soil suction was observed in all cases illustrating the effect of net infiltration process. Positive pore water pressure was even recorded by some of the deeper tensiometers.

After the rain has stopped at $150 \mathrm{~min}$, the suction appears to continue to drop for the next $30 \mathrm{~min}$ or so in particular at location of the shallow tensiometers, followed there after by a gradual rise in suction, albeit at a slow rate as the drying process begins.

The suction recorded by the shallow tensiometers was always higher than those of the deeper tensiometers, indicating a reduction in suction with depth below the ground surface.

In term of weathering grades, residual of weathered sandstone of weathering grade III (at berm 4) has the highest infiltration rate indicating the more porous nature of this soil material. Like wise there is a steeper drop in suction during the rain at this location.

\section{REFERENCES}

1. Brand, E.W., 1984. Landslide in Southeast Asia. Proceedings of $4^{\text {th }}$ International Conference on Landslide. State of the Art Report. Toronto, 1: 1759.

2. Shaw-Shong, L., 2004. Slope failures in tropical residual soil. Chapter 5 in Tropical Residual Soils Engineering. Huat et al., (Ed). Leiden. Balkema, pp: 71-102.

3. Fredlund, D.G. and N.R. Morgenstern, 1977. Stress state variables for unsaturated soils. J. Geotechnical Engineering Division, ASCE., 103: 447-466.

4. Fredlund, D.G. and H. Rahardjo, 1987. Soil mechanics principles for highway engineering in Arid regions. In Soil Mechanics Considerations: Arid and Semiarid areas. Transportation Research Record, 1137: 1-11.

5. Othman, M.A., 1989. Highway cut slope instability problem in West Malaysia. Ph.D. Thesis. University of Bristol. (Unpublished).

6. Anderson, M.G., 1991. Hydrology, slope stability and cut slope design. IEM/PWD, Malaysia: Kuala Lumpur.

7. Affendi. A. and F.H. Ali, 1994. Field measurement of soil suction. Proceeding $13^{\text {th }}$ International Conference on Soil Mechanic and Foundation Engineering. New Delhi, 3: 1013-1016.

8. Suhaimi, A.T., 1997. Comparative study of infiltration in residual soils. Proceeding $4^{\text {th }}$ Regional Conference in Geotechnical Engineering (Geotropika 97). Malaysia, pp: 343-354.

9. Ali, F.H. and H. Rahardjo, 2004. Unsaturated residual soil. Chapter 4 in Tropical Residual Soils Engineering. Huat et al., (Ed). Leiden. Balkema, pp: $57-72$

10. Craig, W.H., B.B.K. Huat and C. Merrifield, 1991. Simulation of climatic conditions in centrifuge model test. Geotechnical Testing J., 14: 406-412.

11. Little, A.L., 1969. The engineering classification of residual tropical soils. Proceedings $7^{\text {th }}$ International Conference Soil Mechanics and Foundation Engineering, Mexico, 1: 1-10.

12. Komoo, I. and S.N. Mogana, 1988. Physical characterization of weathering profiles of clastic metasediments in Peninsular Malaysia. Proceedings $2^{\text {nd }}$ Conference on Geomechanics in Tropical Soils. Singapore, 1: 37-42.

13. Sweeney, D.J., 1982. Some in situ soil suction measurements in Hong Kong's residual soil slopes. Proceedings of $7^{\text {th }}$ S.E.A.G.S. Conference, Hong Kong, 1: 91-106. 